\title{
Vascular involvement in Behçet's disease: Imaging features
}

\author{
Ödev $K^{1 *}$, Varol $S^{1}$ and Tunç $R^{2}$ \\ ${ }^{1}$ Konya Chamber of Commerce Karatay University, Faculty of Medicine, Konya, Turkey \\ ${ }^{2}$ Necmettin Erbakan University, Faculty of Medicine, Konya, Turkey
}

\begin{abstract}
Behçet's disease is multisystemic and chronic inflammatory disorder with an unknown cause. The clinical triad of oral and genital ulcerations and ocular manifestation was originally described by the Turkish dematologist Hulusi Behçet in 1937 .Additional clinical manifestation in other locations (skin,joints,gastrointestinal tract,genitourinery tract,central nervous system,cardiovascular system, lung) were described later. The variability of clinical manifestations and the absence of spesific histologic or laboratory findings may cause the difficultly in diagnosis. The diagnosis is made on the basis of the criteria published in 1990 by the International Study Group for Behçet's disease BD. The main underlying pathologic process in Behçet's disease is vasculitis and perivascular in flammatory infiltrates affecting vessels of different size in various organs.Several types of thoracic involvement associated with Behçet's disease have been described.
\end{abstract}

\section{Introduction}

Behçet's disease is multisystemic and chronic inflammatory disorder with an unknown cause.The clinical triad of oral and genital ulcerations and ocular manifestation was originally described by the Turkish dematologist Hulusi Behçet in 1937 [1]. Additional clinical manifestation in other locations (skin,joints,gastrointestinal tract,genitourinery tract,central nervous system,cardiovascular system,lung) were described later [2]. The variability of clinical manifestations and the absence of spesific histologic or laboratory findings may cause the difficultly in diagnosis.The diagnosis is made on the basis of the criteria published in 1990 by the International Study Group for Behçet's disease BD [3].The main underlying pathologic process in Behçet's disease is vasculitis and perivascular in flammatory infiltrates affecting vessels of different size in various organs [4]. Several types of thoracic involvement associated with Behçet's disease have been described.

This study focuses on the thoracic vascular system involvement of Behçet's disease. We describe Thoracic involvement for one of the most serious aspects of Behçet's disease:Vascular involvement Superior vena cava syndrome,pulmoner parenchmal and mediastinal involvement in the disease.

\section{Involvement of thoracic vessels}

Vascular manifestations of BD,which consist of venous involvem ents(thrombosis,superficial thrombophlebitis,) and arterial involvem ents(aneurysm,stenosis,occlusion), have been added into the update International Criteria for Behçet's Disease,since they are one of the major characteristics of $\mathrm{BD}$ [5].The entire arterial tree can be involved in $\mathrm{BD}$, with aneurysm or pseudoaneuriysm or thrombosis,pulmonary infarction,pulmonary hemorrhage and pulmonary artery aneuriysm. Contrast enhanced helical CT or multislice CT (MSCT)(especially,CT angiography) as a noninvasive and sensitive method for detecting aneurysm has been pointed out in many papers [2,4,6].Systemic arterial manifestations of $\mathrm{BD}$ are infrequent compared with venous involvement.According to the order of frequency vascular involvement is reported in $85 \%$ venous, $10 \%$ arterial and 5\% combined arterial and venous involvement [7] pulmonary artery aneurysms(PAAs): PAAs are the most common type of pulmonary involvement in BD.Hilar enlargement or the appearance of polylobular and round opacities on the chest radiograph or thorax CT can present pulmonary artery aneurysms (Figure 1) [2,6]. Thrombosis of the pulmonary arteries in $\mathrm{BD}$ is usually in situ thrombosis. Although deep vein thrombosis is common in $\mathrm{BD}$, pulmonary embolism is rare because the thrombi in the inflamed veins of the lower extremities are strongly adherent [8]. The association of hemoptysis with dyspne and pleuritic chest pain is suggestive of pulmonary infarction secondary thromboembolism $[2,8,9]$. Hemoptysis of varying degrees is the most common clinical symptom of pulmonary artery aneurysms.It may be life threatening or fatal [2].

\section{Involvement of the superior vena cava and major medi- astinal veins}

Superficial thrombophlebitis and deep vein thrombophlebitis are the most frequent venous manifestations.Involvement of the venous system is most frequently seen in the form of thrombophlebitis Thrombophlebitis can affects veins of the lower extremity, SVC and inferior vena cava [10]. The vascular lesion occurs in the venous system (18-24\%) more frequently than the arterial system(7\%) [11]. The most serious complications in $\mathrm{BD}$ is superior vena cava (SVC) syndrome and Budd Chiari syndrome [12]. Following malignancy, BD is the commonest cause of superior vena cava syndrome in Mediterranean countries $[9,12]$. Helical CT or multislice CT with $3 \mathrm{D}$ volume rendering can document the obstruction of the SVC or major mediastinal veins and the presence enlarged collateral vessels in the mediastinum and chest wall (Figure 2) $[6,13]$. Recent reports suggest that $3 \mathrm{D}$ gadolinium

*Correspondence to: Kemal Ödev, Konya Chamber of Commerce Karatay University, Faculty of Medicine, Akabe Mah, Karatay/Konya Turkey, E-mail: kemalodev50@yahoo.com

Key words: Behçet's disease,Lung,CT,MR angiography,MR venography

Received: April 01, 2019; Accepted: April 08, 2019; Published: April 10, 2019 

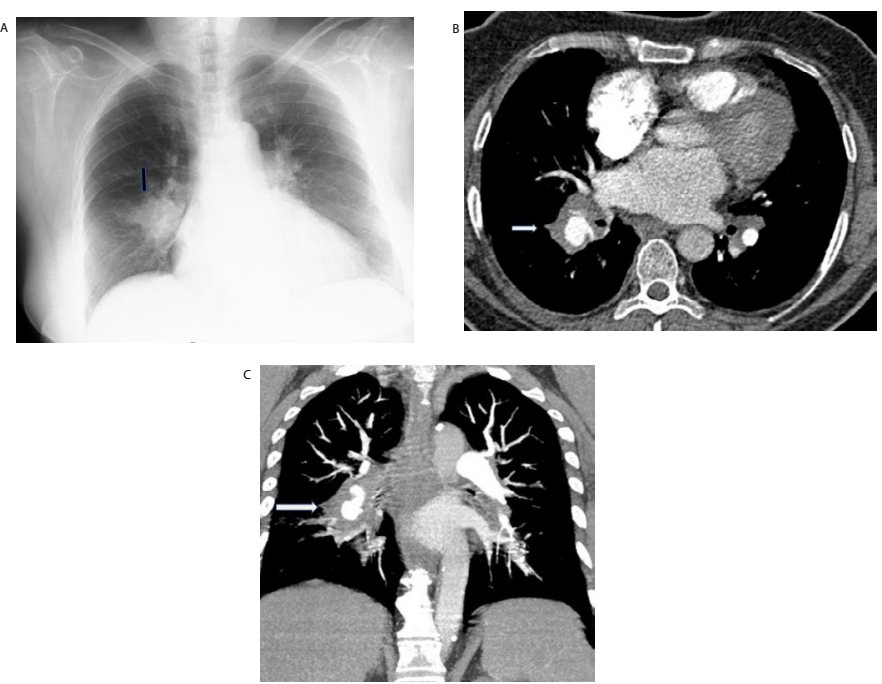

Figure 1. 37-year-old woman with chronic cough, dyspnoea and haemoptysis with known Behçet's disease

A. Initial chest radiograph shows poorly defined round opacity (arrow) at inferior part of hilus on the right (arrow)

B. Axial contrast enhanced chest CT scan ( mediastinal window) shows aneurysm with thrombosis at interlobar pulmonary artery (white arrow)

C. Coronal maximum-intensity projection (MIP) CT image shows right interlobar artery aneurysm (Long arrow)
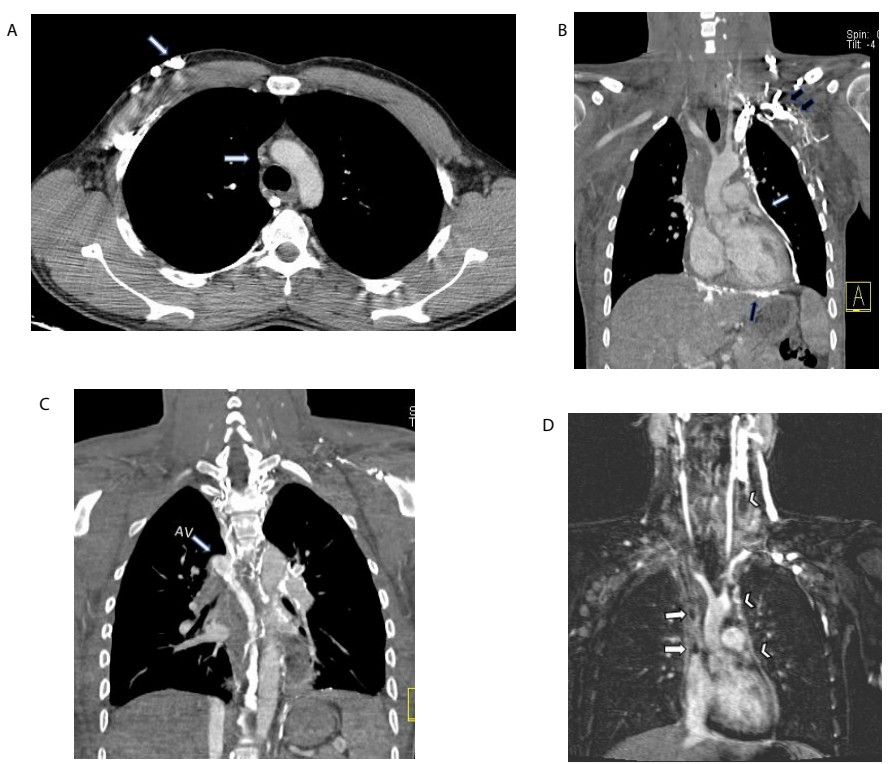

Figure 2. Superior vena cava syndrome due to Behçet's disease in a fifty-year old man with a five-year history of BD

A. Axial contrast enhanced chest CT scan(mediastinal window) shows an occlusion of superior vena cava(SVC) (thin arrow)

B-C. Coronal maximum-intensity projection (MIP) CT image shows collateral vessels in the mediastinum(white arrow) and chest wall (black arrows) and collateral circulation via delated azygos vein (arrow AV)

D. Delayed phase gadolinium-enhanced MR image shows both arterial and venous enhancement.MR imaging reveals occlusion of SVC (black arrows), bilateral axillar,subclavian and innominate veins.Note : Occlusion (nonvisualization) of the neck and both internal jugular veins(white arrow head) and enhancement of multiple mediastinal collateral veins(white arrow heads)

enhanced subtraction MR venography with the subtraction of arterial phase images also may be useful in the evaluation of the entire central venous system and may be used in patients who were suspected of having thoracic venous occlusion due to in a variety of benign and malign conditions, such as inflammation, hyperalimentation, fibrosis, hemodialysis or neoplasms [14,15]. Moreover, Erkan et.al. [2,5] suggest that MR imaging is also a non-invasive and sensitive method for demonstrating of vena cava occlusion (Figure 2).

\section{Involvement of the pulmonary parenchyma}

Involvement of Behçet disease in the pulmonary parenchyma and pleura is seen in $1-10 \%$ of patients during the course of Behçet's disease $[13,16]$. On the plain chest film or thorax CT visible abnormalities include air-space consolidation,pulmonary infarcts, pulmonary hemorrhage, atelectasis, cryptogenic organizing pneumonia transient focal or diffuse alveolar infiltrates, wedge-shaped opacities, rounded opacities and excavated nodul.These radiological abnormalities are nonspecific $[2,4]$.

\section{Involvement of the heart and mediastinum}

Intracardiac thrombosis is a rare but serious complication of Behçet's disease [6]. In a case with Behçet's disease pulmonary artery aneurysm accompanied with intracardiac thrombosis and in the other case coronary artery aneurysm associated with PAA have been reported [17]. The other pulmonary complication of $\mathrm{BD}$ is mediastinal fibrosis in association with occlusion of SVC. This complicated clinical entity has rarely been described [12,18]. Because radiologic features of mediastinal involvement with SVC syndrome in $\mathrm{BD}$ are similar to those of benign and malignant conditions, such as radiation theraphy, trauma, tuberculosis, fungal infections, rheumatic fever and neoplasms. However, these clinical entities must be clinically differentiated [18].

\section{References}

1. Behçet H (1937) Uber rezidivierende, aphthose, durchein Virus verusachte Gaschwure am Mund, am Auge und an den Genitalien. Dermatol Wochensch 105: 1152-1157.

2. Erkan F, Gül A, Tasali E (2002) Pulmonary manifestations of Behçet's disease. Thorax 23: 493-503.

3. [No authors listed] (1990) Criteria for diagnosis of Behçet's disease. International Study Group for Behçet's Disease. Lancet 335: 1078-1080. [Crossref]

4. Hiller N, Lieberman S, Chajek-Shaul T, Bar-Ziv J, Shaham D (2004) Thoracic manifestations of Behçet disease at CT. Radiographics 24: 801-808. [Crossref]

5. Davatchi F, Assaad-Khalil S, Calamia KT, Crook JE, Sadeghi-Abdollahi, et al. (2014) The International Criteria for Behçet's Disease (ICBD): a collaborative study of 27 countries on the sensitivity and specificity of the new criteria. $J$ Eur Acad Dermatol Venerol 28: 338-347. [Crossref]

6. Erkan F (1999) Pulmonary involvement in Behçet disease. Curr Opin Pulm Med 5 314-318.

7. Kabbaj N, Benjelloun G, Gueddari FZ, Dafiri R, Imani F (1993) [Vascular involvements in Behçet disease. Based on 40 patient records]. J Radiol 74: 649-656. [Crossref]

8. Durieux P, Bletry O, Huchon G, Wechsler B, Chretien J, et al. (1981) Multiple pulmonary arterial aneurysms in Behcet's disease and Hughes-Stovin syndrome. Am J Med 71: 736-741. [Crossref]

9. Hamuryudan V, Yurdakul S, Moral F, Numan F, Tüzün H, et al. (1994) Pulmonary arterial aneurysms in Behçet's syndrome: a report of 24 cases. Br J Rheumatol 33: 4851. [Crossref]

10. Sağdiç K, Ozer ZG, Saba D, Ture M, Cengiz M (1996) Venous lesions in BehÃßet's disease. Eur J Vasc Endovasc Surg 11: 437-440. [Crossref]

11. El-Ramani KM, Al-Dalaan A, Al-Balaa S (1993) Vascular involvement in Behçet's disease.In: Wechsler B, Godeau P eds. Behçet's disease. Amsterdam: Excerpta Medica 531.

12. Dündar S,Yazici H (1984)) Superior Vena Cava Syndrome in Behcet's Disease Vascular Surg 18:29-30. 
13. Ceylan N, Bayraktaroglu S, Erturk SM, Savas R, Alper H (2010) Pulmonary and vascular manifestations of Behcet disease: imaging findings. AJR Am J Roentgenol 194: W158-W164. [Crossref]

14. Shinde TS, Lee VS, Rofsky NM, Krinsky GA, Weinreb JC (1999) Three-dimensional gadolinium-enhanced MR venographic evaluation of patency of central veins in the thorax: initial experience. Radiology 213: 555-560. [Crossref]

15. Hansen ME, Spritzer CE, Sostman HD (1990) Assessing the patency of mediastinal and thoracic inlet veins: value of MR imaging. AJR Am J Roentgenol 155: 1177-1182. [Crossref]
16. Fairley C, Wilson JW, Barraclough D (1989) Pulmonary involvement in Behçet's syndrome. Chest 96: 1428-1429. [Crossref]

17. Yakut ZI, Odev K (2007) Pulmonary and cardiac involvement in Behçet disease: 3 case reports. Clin Appl Thromb Hemost 13: 318-322. [Crossref]

18. Harman M, Sayarlioglu M, Arslan H, Ayakta H, Harman E (2003) Fibrosing mediastinitis and thrombosis of superior vena cava associated with Behçet's disease. Eur J Radiol 48: 209-212. [Crossref]

Copyright: $@ 2019$ Ödev K. This is an open-access article distributed under the terms of the Creative Commons Attribution License, which permits unrestricted use, distribution, and reproduction in any medium, provided the original author and source are credited. 